\title{
Achados clínico patológicos durante um surto de disenteria de inverno em bovinos no Rio Grande do Sul ${ }^{1}$
}

\author{
Saulo Petinatti Pavarini², Pedro Soares Bezerra Junior², Adriana da Silva \\ Santos ${ }^{2}$, Caroline Argenta Pescador ${ }^{2}$, Paulo Eduardo Brandão ${ }^{3,4}$, Sibele \\ Pinheiro de Souza ${ }^{3}$ e David Driemeier ${ }^{*}$
}

\begin{abstract}
Pavarini S.P., Bezerra Junior P.S., Santos A.S., Pescador C.A. \& Driemeier D. 2008. [Clinic pathological features during a winter dysentery outbreak in cattle in Rio Grande do Sul.] Achados clínico patológicos durante um surto de disenteria de inverno em bovinos no Rio Grande do Sul. Pesquisa Veterinária Brasileira 28(12):611616. Departamento de Patologia Clínica Veterinária, Universidade Federal do Rio Grande do Sul, Av. Bento Gonçalves 9090, Porto Alegre, RS 91540-000, Brazil. E-mail: davetpat@ufrgs.br

The report describes a winter dysentery outbreak that affected 10 dairy cows from a ranch located in the county of Viamão, Rio Grande do Sul. The most significant clinical sign was profuse and watery diarrhea, which ranged from a greenish to a brownish coloration and from occasional blood streaks with mucus to a bloody diarrhea. Most cases persisted for 5 days and also included depression, drastic decrease in milk production and in food consumption. Only one of the affected animals died. The necropsy revealed pale mucosa and sanguineous content with high quantity of blood clots, particularly within the spiral colon, and petechiae on the colonic mucosa. Histopathological lesions were predominant in the spiral colon, and consisted of a high number of dilated crypts without epithelium or with the replacement of a pavement epithelium with occasional immature cuboidal cells, which sometimes showed enlarged nucleus and proeminent nucleolus. Some crypts were filled with epithelial desquamation and polymorphnuclear cells. Bovine coronavirus (8F2) monoclonal antibody was used for immunohistochemistry on sections of the spiral colon that showed positive reactions in the cytoplasm of the infected crypt epithelium, sloughed necrotic cells, and within macrophages in the lamina propria of both.
\end{abstract}

INDEX TERMS: Winter dysentery, diarrhea, spiral colon, bovine coronavirus.

RESUMO.- Descreve-se um surto de disenteria de inverno que afetou 10 vacas leiteiras de uma propriedade localizada em Viamão, Rio Grande do Sul. O quadro clínico caracterizou-se por uma diarréia inicialmente líquida

\footnotetext{
${ }^{1}$ Recebido em 19 de maio de 2008.

Aceito para publicação em 16 de julho de 2008.

2 Departamento de Patologia Clínica Veterinária, Universidade Federal do Rio Grande do Sul (UFRGS), Av. Bento Gonçalves 9090, Porto Alegre, RS 91540-000, Brasil. *Autor para correspondência: davetpat@ufrgs.br

${ }^{3}$ Faculdade de Medicina Veterinária e Zootecnia (FMVZ), Universidade de São Paulo (USP), Av. Prof. Dr. Orlando Marques de Piava 87, Cidade Universitária, São Paulo, SP 05508-270, Brasil.

${ }^{4}$ Coronavirus Research Group, FMVZ-USP, Av. Prof. Dr. Orlando Marques de Paiva 87, Cidade Universitária, São Paulo, SP.
}

esverdeada com estrias de sangue e muco, evoluindo, em alguns animais, para uma diarréia de coloração marrom escura à sanguinolenta, que persistiu, em média, cinco dias. Drástica diminuição na produção de leite e no consumo de alimentos, além de graus variados de depressão também foram observados. Apenas um dos 10 animais afetados morreu. Durante a necropsia, observaramse mucosas pálidas, conteúdo sanguinolento com presença de grande quantidade de coágulos, principalmente no cólon espiral e petéquias na mucosa do cólon. Os principais achados histológicos foram encontradas no cólon espiral, onde havia criptas dilatadas, sem epitélio de revestimento ou revestidas por epitélio pavimentoso e/ou cuboidal, por vezes com núcleos grandes e nucléolos proeminentes. Algumas criptas eram preenchidas por debris 
necróticos e polimorfonucleares. Na imuno-histoquímica com anticorpo monoclonal para coronavírus bovino (8F2) em cortes do cólon espiral, havia marcações positivas no citoplasma de enterócitos das criptas, nos debris necróticos destas e em macrófagos na lâmina própria.

TERMOS DE INDEXAÇÃO: Disenteria de inverno, diarréia, cólon espiral, coranavírus bovino.

\section{INTRODUÇÃO}

A disenteria de inverno é uma doença altamente contagiosa que afeta freqüentemente bovinos adultos durante a estação fria. A síndrome clínica inclui disenteria profusa de surgimento agudo, fezes esverdeadas com estrias de sangue, sanguinolentas ou marrom-escuras, redução da produção de leite, graus variáveis de depressão, anorexia e sinais respiratórios. Freqüentemente a recuperação espontânea dos animais ocorre em poucos dias e, no rebanho, a duração da doença é de algumas semanas. Usualmente apresenta morbidade alta (50-100\%) e mortalidade baixa (0-2\%) e os relatos de afecção em bezerros durante os surtos são contraditórios (Roberts 1957, Campbell \& Cookingham 1978, Van Kruiningen et al. 1985, Saif 1990, Cho et al. 2000, Natsuaki et al. 2007).

A doença afeta principalmente gado leiteiro (Roberts 1957, Campbell \& Cookingham 1978, Van Kruiningen et al. 1985, Saif et al. 1988, Saif, 1990, Saif et al. 1991, Travén et al. 1993, Natsuaki et al. 2007), mas também já foi descrita em gado de corte manejado a campo (Espinasse et al. 1982) ou em confinamentos (Cho et al. 2000).

No passado a enfermidade foi associada a diversos agentes como a bactéria Campylobacter (Vibrio) jejuni e a agentes virais, como enterovírus (WD-42), parvovírus bovino, vírus da rinotraqueíte infecciosa bovina e vírus da diarréia viral bovina (BVDV) (Saif 1990).

Desde a década de 70 vários trabalhos vêm apontando o envolvimento do coronavírus bovino (BCoV) nos surtos de disenteria de inverno pela detecção do vírus nas fezes de animais enfermos e/ou pelo acompanhamento da soroconversão dos animais durante os surtos (Horner et al. 1975, Takahashi et al. 1980, Espinasse et al. 1982, Van Kruiningen et al. 1987, Saif et al. 1988, 1991).

Reforçando o envolvimento do coronavírus bovino nesta doença, Van Kruiningen et al. (1987) demonstraram a presença do vírus nas lesões intestinais e Travén et al. (2001) reproduziram uma doença clínica comparável à disenteria de inverno em vacas e bezerros soronegativos para o vírus com material oriundo de casos naturais da doença.

Surtos similares têm sido descritos em muitos países, principalmente na zona temperada do hemisfério norte, mas também no hemisfério sul (Horner et al. 1975, Campbell \& Cookingham 1978). No Brasil, a detecção de coronavírus nas fezes de vacas adultas com diarréia foi relatada por Brandão et al. (2002, 2007a,b) no estado de São Paulo.

Este artigo relata um surto de disenteria de inverno em bovinos no Rio Grande do Sul, as alterações clinico- patológicas apresentadas pelos animais acometidos pela doença, a pesquisa de patógenos e a presença do coronavírus bovino em células do trato intestinal pela técnica de imunohistoquímica.

\section{MATERIAL E MÉTODOS}

Dados epidemiológicos e sinais clínicos da enfermidade foram obtidos com o proprietário e o veterinário do rebanho. Amostras de tecidos foram coletadas durante a necropsia de um animal que morreu pela doença (Bovino 1), fixadas em formol a $10 \%$ tamponado, desidratadas em concentrações crescentes de álcool etílico, diafanizados em xilol e incluídas em parafina. Cortes de $5 \mathrm{~mm}$ foram corados pela hematoxilina e eosina (HE) (Prophet et al. 1992).

Fragmentos de cólon ascendente na altura da alça espiral (cólon espiral), cólon descendente, ceco, íleo, jejuno, duodeno, linfonodos mesentéricos e pulmão foram submetidos ao teste de imunohistoquímica utilizando anticorpo monoclonal para coronavírus bovino (8F2) na diluição de 1:300 em Phosphate Buffered Saline (PBS), empregando-se o método streptavidina-biotina (LSAB). Para recuperação antigênica, utilizou-se solução de tampão citrato $(\mathrm{PH} \mathrm{6,0)}$ por 20 minutos em banho-maria à $100^{\circ} \mathrm{C}$. Leite desnatado diluído a $5 \%$ em PBS foi utilizado para bloqueio de reações inespecíficas. O cromógeno foi VECTOR®NovaRED e a contra-coloração foi feita com hematoxilina. O anticorpo foi obtido comercialmente dos EUA da empresa Rural Technologies Inc., South Dakota, USA. Simultaneamente, cortes de cólon espiral com lesão foram incubados com PBS e cortes de cólon espiral sem lesão, com anticorpo para coronavírus bovino (8F2), como controles. Fragmentos de orelha e de intestino foram submetidos ao teste imunohistoquímico com anticorpo monoclonal anti-BVDV (15CS Syracuse) na diluição de 1:500 pelo método streptavidina-biotina. Para recuperação antigênica, foi utilizado Protease XIV de Streptomyces griseus (Sigma, Chemical Co., St Louis, Mo) a 0,005\% em PBS por 15 minutos em câmara úmida. VECTOR®NovaRED foi o cromógeno utilizado (Njaa et al. 2000, Schmitz 2006). Controles positivos foram inseridos simultaneamente (Schmitz 2006). Amostras de fezes foram colhidas do reto de animais afetados (Bovinos 1 e 2) para exame bacteriológico aeróbico, para Salmonella sp. em meio específico (Koneman et al. 2001) e exame parasitológico incluindo contagem de ovos (o.p.g.) e oocistos por grama de fezes (o.p.g.) (Ueno \& Gonçalves 1998). Variações da temperatura nos dias da ocorrência do surto foram obtidas no Instituto Nacional de Meteorologia (INMET 2007). Sangue de uma vaca afetada (Bovino 2) foi coletado 3 dias após o início do quadro clínico para hemograma.

Para a pesquisa de coronavírus bovino (BCoV), amostras fecais dos Bovinos 1 e 2 foram inicialmente preparadas como suspensões a $20 \%(\mathrm{v} / \mathrm{v})$ em água ultra-pura tratada com $0,1 \%$ de dietil-pirocarbonato (água DEPC) e clarificadas por centrifugação a $12.000 \times$ g/30min a $4^{\circ} \mathrm{C}$. A seguir, aplicou-se uma reação de transcrição reversa seguida de reação em cadeia pela polimerase nested (nested RT-PCR) para a amplificação de um segmento de 136 pares de bases $(\mathrm{pb})$ do gene codificador da RNA-polimerase RNA-dependente $(R d R p)$ conforme descrito por Brandão et al. (2007a), utilizando-se como controle positivo a amostra Kakegawa de BCoV (Akashi et al. 1980) e, como negativo, água DEPC. 


\section{RESULTADOS}

Em uma propriedade rural localizada no município de Viamão, Rio Grande do Sul, durante o mês de abril de 2006, dez de um total de 24 vacas leiteiras adultas apresentaram diarréia profusa sanguinolenta, dos quais uma vaca de 7 anos morreu (Bovino 1). Todas as dez vacas que apresentaram diarréia eram mantidas separadas do resto do rebanho em um piquete com pastagem de milheto de melhor qualidade, por apresentarem melhores índices de produção leiteira. As demais ficavam em outro piquete de campo nativo, mas todo rebanho era suplementado (silagem de milho, bagaço de malte e ração comercial) no mesmo cocho durante a ordenha. A ordenha dos dois grupos de animais era feita separadamente. Os animais foram imunizados contra febre aftosa, brucelose, leptospirose, carbúnculo hemático e diarréia bovina a vírus (BVD).

A diarréia, de surgimento agudo, foi inicialmente acompanhada por graus variáveis de depressão (Fig.1) e apresentou-se esverdeada com muco e às vezes acompanhada com estrias de sangue e evoluiu para uma diarréia sanguinolenta ou marrom-escuro (Fig.2). Os sinais persistiram por aproximadamente cinco dias, sendo mais evidentes do segundo ao quarto dias. Drástica diminuição (cerca de $50 \%$ ) na produção de leite e diminuição na ingestão de alimentos foi verificada neste período. Durante o surto, não foi observada diarréia nos bezerros.

$\mathrm{Na}$ necropsia da vaca que morreu pela diarréia (Bovino 1) observou-se palidez das mucosas oral, ocular e vaginal. Havia desidratação acentuada caracterizada por olhos no fundo das órbitas e a pele apresentava perda da elasticidade. Conteúdo sanguinolento com grande quantidade de coágulos foram encontrados no intestino grosso principalmente no cólon espiral com petéquias na mucosa (Fig.3). Os principais achados histológicos foram vistos no cólon espiral e consistiram de grande número de criptas dilatadas, desnudas ou revestidas por um

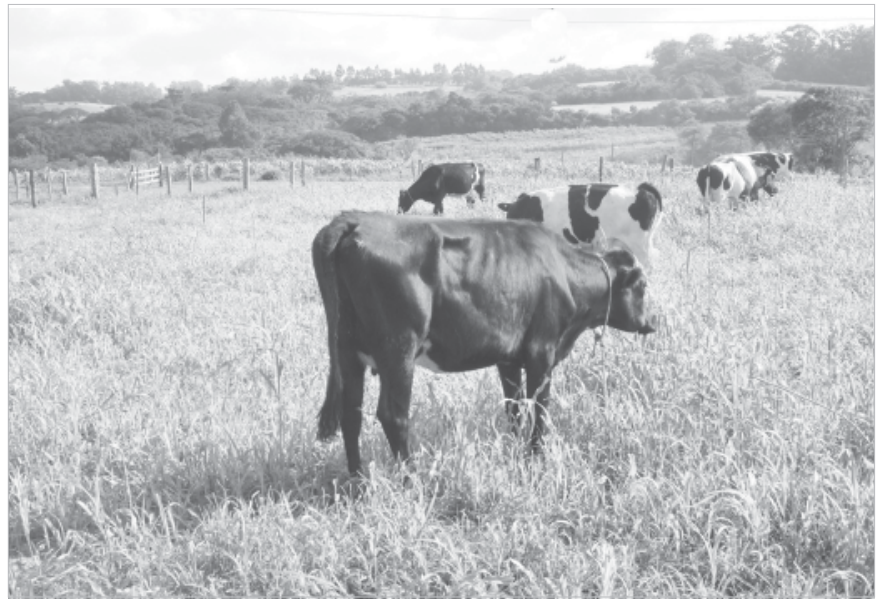

Fig.1. Animal doente com apatia, abdômen flácido e perda de condição corporal mais afetado em comparação com os demais (Bovino 2).

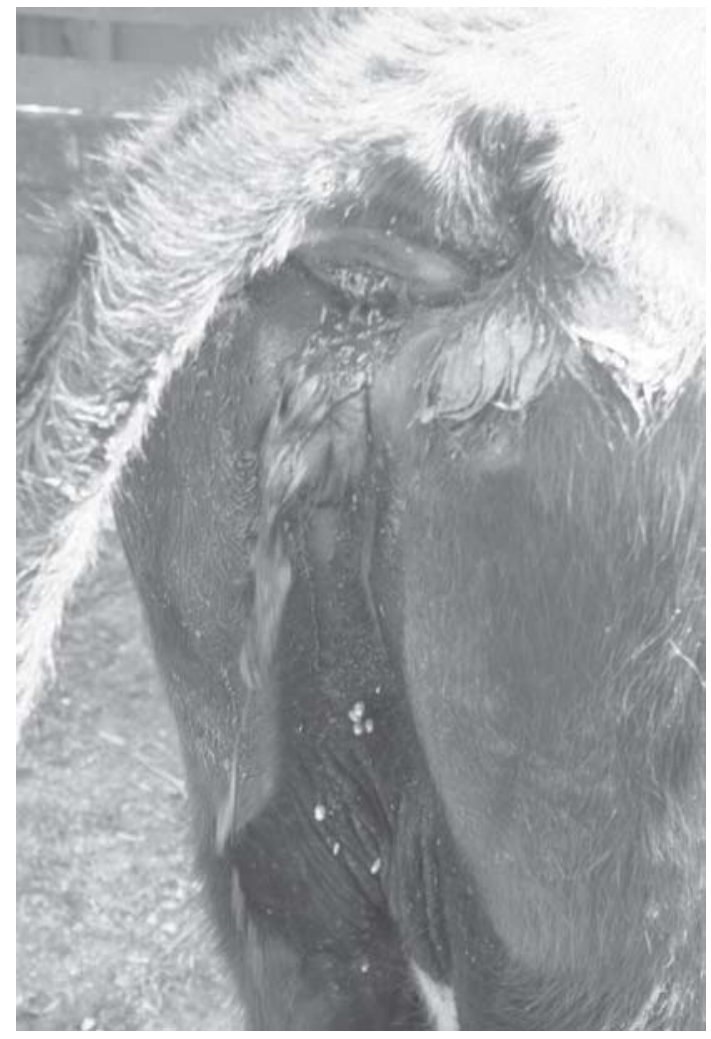

Fig.2. Vaca apresentando diarréia líquida sanguinolenta (Bovino 2).

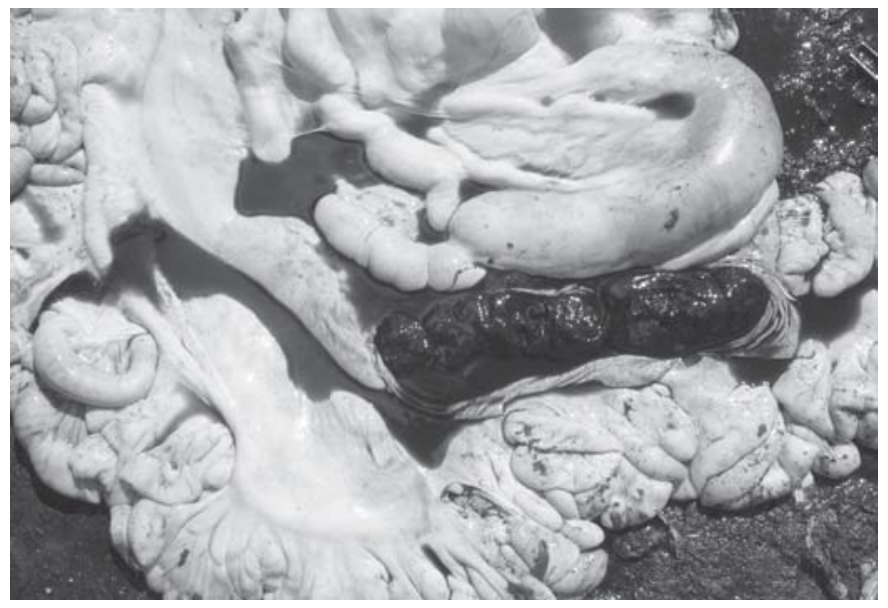

Fig.3. Cólon espiral distendido por coágulos de sangue presentes no lúmen (Bovino 1).

epitélio pavimentoso e/ou cuboidal, por vezes com núcleos grandes e nucléolos proeminentes. Algumas criptas estavam preenchidas por debris necróticos e polimorfonucleares (Fig.4). Na lâmina própria havia infiltrado inflamatório moderado, constituído predominantemente por linfócitos e, em menor número, por macrófagos, plasmócitos e eosinófilos. Na submucosa foi observado infiltrado semeIhante, porém de menor intensidade. Não houve crescimento bacteriológico significativo e os exames parasitológicos de o.p.g. e o.o.p.g. não foram expressivos. 


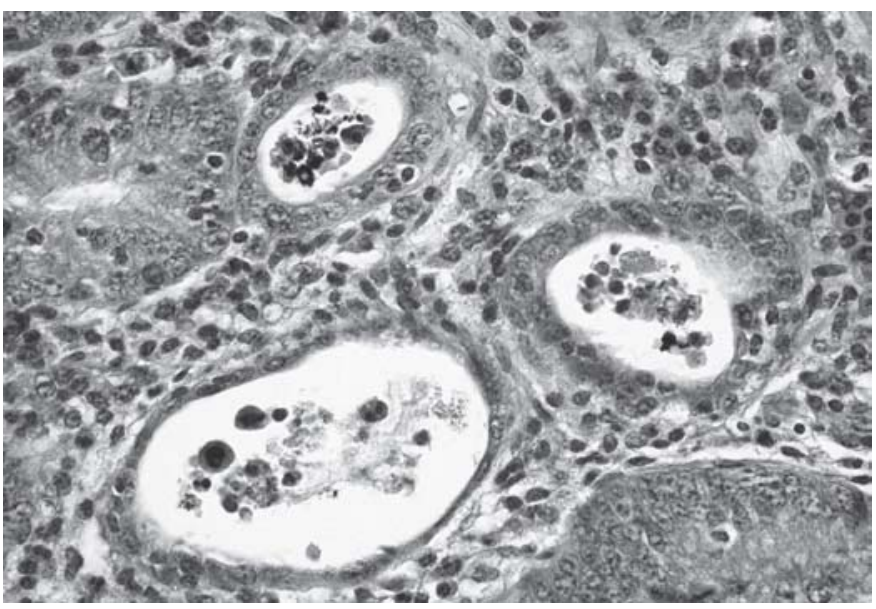

Fig.4. Cólon espiral com criptas dilatadas, revestidas por epitélio pavimentoso ou cuboidal e preenchidas por debris necróticos e infiltrado mononuclear com eosinófilos na lâmina própria (Bovino 1). HE, obj.40x.

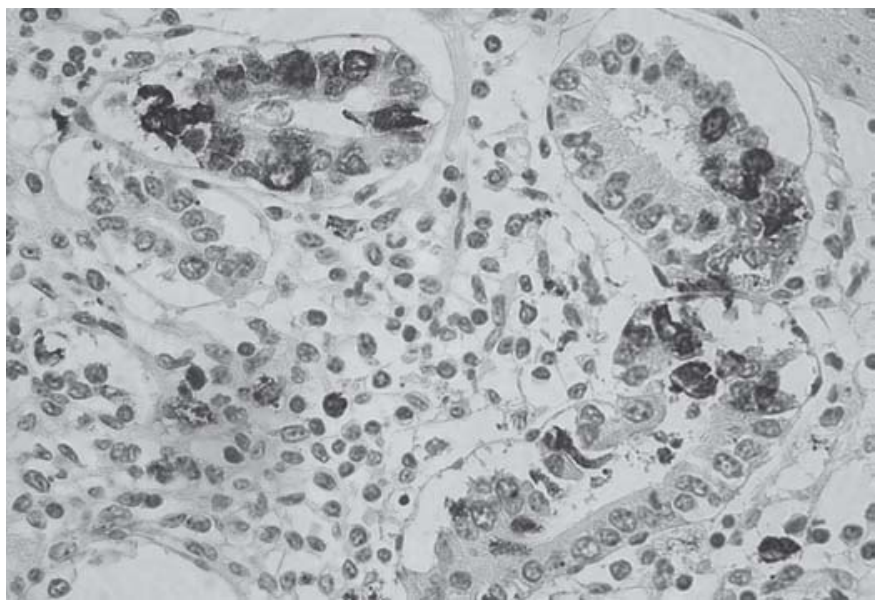

Fig.5. Imunohistoquímica com anticorpo monoclonal anti coronavírus bovino demonstrando, no cólon espiral, a presença de antígeno viral em enterócitos e macrófagos e debris necróticos no lúmen das criptas (Bovino 1). Método streptavidina-biotina, cromógeno Vector Nova Red, obj.40x.

$\mathrm{Na}$ imuno-histoquímica anti-coronavírus bovino (8F2), somente em cortes do cólon espiral houve marcações, as quais foram mais evidentes no citoplasma de enterócitos das criptas, nos debris necróticos e em macrófagos na lâmina própria (Fig.5). Não houve marcação nos fragmentos de orelha e intestinos submetidos à imuno-histoquímica anti-BVDV. A temperatura do ambiente durante a semana do surto variou de $24^{\circ} \mathrm{C}$ a $16^{\circ} \mathrm{C}$ e não houve chuvas (INMET 2007). O hemograma de uma vaca afetada (Bovino 2) revelou anemia (hematócrito 19\%) normocítica, normocrômica e leucocitose (leucócitos totais 20700/ $\mathrm{mm}^{3}$ ) com neutrofilia $\left(7245 / \mathrm{mm}^{3}\right.$ de segmentados) e linfocitose (linfócitos 12627/mm³). Os neutrófilos apresentavam evidências de toxicidade.

As duas amostras fecais (Bovinos 1 e 2 ) foram positivas para a nested RT-PCR para a detecção de BCoV, tendo resultado na produção da banda esperada de 136pb, bem como a amostra padrão Kakegawa, sendo que nos controles negativos não se evidenciou qualquer banda.

\section{DISCUSSÃO E CONCLUSÃO}

Os achados epidemiológicos e clínico-patológicos apresentados pelos animais desse surto são muito semelhantes aos descritos na doença denominada disenteria de inverno (Roberts 1957, Campbell \& Cookingham 1978, Van Kruiningen et al. 1985, Saif 1990, Cho et al. 2000, Natsuaki et al. 2007). A presença de antígenos do coranavírus bovino nas lesões colônicas do Bovino 1 e a detecção pela técnica de PCR para coronavírus nos Bovinos 1 e 2 são evidências adicionais do envolvimento do coronavírus nessa doença, principlamente levando-se em conta que a pesquisa bacteriológica e parasitológica não produziu resultados significativos para outros possíveis patógenos.

Entre os vários fatores predisponentes para a disenteria de inverno, as quedas bruscas de temperatura são os mais comuns (Roberts 1957, Campbell \& Cookingham 1978). Entretanto, a pequena variação da temperatura ambiente durante o surto $\left(16-24^{\circ} \mathrm{C}\right)$ (INMET 2007) pode não ter sido decisiva no surgimento da doença, visto que Travén et al (2001) também não constatou a influência da temperatura ambiental como fator predisponente.

As vacas jovens são mais freqüentemente afetadas e a doença tende a ser mais intensa em vacas prenhes ou recém paridas e em lactação (Roberts 1957, Campbell \& Cookingham 1978, Van Kruiningen et al. 1985, Saif 1990). As vacas afetadas no presente surto, em concordância com a literatura, estavam justamente em início de lactação, período de ascendência da curva de produção.

Diarréia profusa, esverdeada com estrias de sangue, sanguinolenta ou marrom-escuro, alta morbidade, baixa mortalidade, curso de 5 dias, diminuição na produção de leite, depressão e diminuição no consumo de alimento são todos sinais compatíveis com os descritos em casos de disenteria de inverno (Roberts 1957, Campbell \& Cookingham 1978, Van Kruiningen et al. 1985, Saif 1990, Cho et al. 2000, Natsuaki et al. 2007). A perda de sangue através das lesões intestinais foi provavelmente a causa da morte do Bovino 1 e a anemia foi constatada no Bovino 2 através do hemograma. As alterações observadas no leucograma, neutrofilia associada à presença de neutrófilos tóxicos e linfocitose, indicam toxicidade medular e estimulação antigênica, respectivamente.

As lesões histológicas observadas nas criptas do cólon espiral são idênticas às descritas na disenteria de inverno de bovinos (Van Kruiningen et al. 1985, 1987, Cho et al. 2000, Natsuaki et al. 2007). A marcação positiva na imuno-histoquímica anti-coronavírus bovino associada com lesões no caso fatal comprova a atuação do vírus nesse surto (Van Kruiningen et al. 1987, Zhang et al. 1997, Dar et al. 1998, Cho et al. 2000, Natsuaki et al. 2007).

Devido à baixa mortalidade ocasionada freqüentemente pela doença, sua correlação com o coronavírus bovino 
tem sido feita pela detecção deste nas fezes e pela soroconversão dos animais de rebanhos afetados (Saif 1990). Para tal, as técnicas que têm sido empregadas incluem, microscopia eletrônica direta (Saif et al. 1991, Athanassious et al. 1994, Dar et al. 1998), ensaio imunoenzimático (ELISA) (Athanassious et al. 1994, Smith et al. 1996, Cho et al. 2000, Jeong et al. 2005), RT-PCR (Brandão et al. 2002, Jeong et al. 2005, Brandão et al. 2007a,b, Natsuaki et al. 2007), imuno-microscopia eletrônica (Athanassious et al. 1994, Cho et al. 2000, Jeong et al. 2005) e isolamento viral in vitro (Sai 1990, Jeong et al. 2005, Natsuaki et al. 2007). No entanto, ainda há controvérsias sobre a relação da detecção do coronavírus nas fezes de animais com a doença clínica, visto que há relatos da presença do vírus nas fezes de animais clinicamente normais, com picos de eliminação nos meses de inverno e próximo do parto (Collins et al. 1987, Clark 1993, Radostits et al. 2000). Assim, a detecção do vírus nas lesões de vacas enfermas, como a realizada no presente estudo, é de grande importância para estabelecer o papel do coronavírus bovino na enfermidade (Saif 1990).

No Brasil, há históricos de surtos de diarréia em bovinos adultos em diferentes regiões, porém os estudos etiológicos nestes casos são escassos. A associação de surtos de diarréia com coronavírus bovino foi estabelecida por Brandão et al. (2002, 2007a,b) que detectou, por hemaglutinação/inibição da hemaglutinação e por RTPCR, o vírus em amostras fecais de vacas afetadas no estado de São Paulo.

Os principais diagnósticos diferenciais dessa enfermidade são infecção aguda por BVD, salmonelose e coccidiose (Radostits et al. 2000). No presente caso, os resultados da imuno-histoquímica anti-BVDV, dos exames bacteriológicos e parasitológicos excluíram tais possibilidades.

Devido à baixa mortalidade causada pela doença, os exames histológicos das lesões são escassos (Van Kruiningen et al. 1985, Van Kruiningen et al. 1987, Cho et al. 2000, Natsuaki et al. 2007), o que, muitas vezes, impede pesquisas mais aprofundadas acerca da patogenia de BCoV. Neste sentido, os dados de histopatologia, incluindo a imuno-histoquímica, aqui apresentados contribuem para demonstrar os sítios preferenciais de replicação do BCoV no trato digestivo dos bovinos, o que é essencial para o entendimento dos sintomas, visto que a replicação intensa do vírus nas células de cripta foi provavelmente a causa da intensa eliminação de sangue nas fezes aqui descrita.

Os dados do presente estudo demonstram a importância do coronavírus bovino como causa de doença entérica em bovinos adultos no estado do Rio Grande do Sul, fato que deve ser levado em conta de agora em diante no delineamento de medidas profiláticas que impeçam os prejuízos econômicos à pecuária leiteira gerados pela disenteria de inverno.

Agradecimentos.- Ao Dr. Sanjay Kapil, Oklahoma State University, USA, pelo auxílio técnico na imuno-histoquímica. Ao CNPq e à CAPES pela concessão de bolsas aos mestrandos e doutorandos do Setor de Patologia Veterinária.

\section{REFERÊNCIAS}

Athanassious R., Marsolais G., Assaf R., Dea S., Descôteaux J.P., Dulude S. \& Montpetit C. 1994. Detection of bovine coronavirus and type A rotavirus in neonatal calf diarrhea and winter dysentery of cattle in Quebec: evaluation of three diagnostic methods. Can. Vet. J. 35(3): 163-169.

Brandão P.E., Birgel Jr E.H., Gregori F., Rosales C.A.R., Ruiz V.L.A. \& Jerez J.A. 2002. Bovine coronavirus detection in adult cows in Brazil. Arqs Inst. Biológico, São Paulo, 69(2):103-104.

Brandão P.E., Gregori F., Sforsin A.J., Villarreal L.Y.B. \& Jerez J.A. 2007a. Winter dysentery in cows associated with bovine coronavirus (BCoV). Arq. Bras. Med. Vet. Zootec. 59(4):1074-1076.

Brandão P.E., Villarreal L.Y.B., Gregori F., Souza S.L.P., Lopes M.A.E., Gomes C.R., Sforsin A.J., Sanches A.A., Rosales C.A.R., Richtzenhain L.J., Ferreira A.J.P. \& Jerez J.A. 2007b. On the etiology of an outbreak of winter dysenter dysentery in dairy cows in Brazil. Pesq. Vet. Bras. 27(10):398-402.

Campbell S.G. \& Cookingham C.A. 1978. The enigma of winter dysentery. Cornell Vet. 68(4):423-441.

Cho K.-O., Albur P.G., Bruna J.D., Sorden S.D., Ion K.-J., Janke B.H., Chang K.O. \& Saif L.J. 2000. Detection and isolation of coronavirus from feces of three herds of feedlot cattle during outbreaks of winter dysentery-like disease. J. Am. Vet. Med. Assoc. 217(8):1191-1194.

Clark M.A. 1993. Bovine coronavirus. Brit. Vet. J. 149(1):51-70

Collins J.K., Riegel C.A., Oslon J.D. \& Foutain A. 1987. Shedding of enteric coronavirus in adult cattle. Am. J. Vet. Res. 48(3):361-365.

Dar A.M., Kapil S. \& Goyal S.M. 1998. Comparison of immunohistochemistry, electron microscopy, and direct fluorescent antibody test for detection of bovine coronavirus. J. Vet. Diagn. Invest. 10(2):152-157.

Espinasse J., Viso M., Laval A., Savey M. \& Le Layec C.L. 1982. Winter dysentery: a coronavirus-like agent in the faeces of beef and dairy cattle with diarrhoea. Vet. Rec. 110(16):385.

Horner G.W., Hunter R. \& Kirkbride C.A. 1975. A coronavirus-like agent present in faeces of cows with diarrhoea. N. Z. Vet. J. 23(5):98.

INMET 2007. Normais Climatológicas. Instituto Nacional de Meteorologia. Capturado em 17 de out. Online. Disponível na Internet http:// www.inmet.gov.br

Jeong J.-H., Kim G.-Y., Yoon S.-S., Park S.-J., Kim Y.-J., Sung C.-M., Jang O.-J., Shin S.-S., Koh H.-B., Lee B.-J., Lee C.-Y., Kang M.I., Kim H.-J., Park N.-Y. \& Cho K.-O. 2005. Detection and isolation of Winter Dysentery Bovine Coronavírus circulated in Korea during 20022004. J. Vet. Med. Sci. 67(2):187-189.

Koneman E.W., Allen S.D., Janda W.M., Schreckenberger P.C. \& Win Jr W.C. 2001. Diagnóstico Microbiológico. 5ª ed. MEDSI, São Paulo. $1465 \mathrm{p}$.

Natsuaki S, Goto K., Nakamura K., Yamada M., Ueo H., Komori T., Shirakawa H. \& Uchinuno Y. 2007. Fatal Winter Dysentery with severe anemia in an adult cow. J. Vet. Med. Sci. 69(9):957-960.

Njaa B.L., Clark E.G., Janzen E., Ellis J.A. \& Haines D.M. 2000. Diagnosis of persistent bovine viral diarrhea virus infection by immunohistochemical staining of formalin-fixed skin biopsy specimens. J. Vet. Diagn. Invest. 12(5):393-399.

Prophet E.B., Mills B., Arrington J.B. \& Sobin L.H. 1992. Laboratory Methods in Histotechnology. Armed Forces Institute of Pathology, American Registry of Pathology, Washington, DC. 279p.

Radostits O.M., Gay C.C., Blood D.C. \& Hinchcliff K.W. 2000. Veterinary Medicine: A textbook of the diseases of cattle, sheep, pigs, goats and horses. $9^{\text {th }}$ ed. W.B. Saunders, London. 1877p.

Roberts S.J. 1957. Winter dysentery in dairy cattle. Cornell Vet. 47(3):372-388. 
Saif L.J. 1990 A review of evidence implicating bovine coronavirus in the etiology of winter dysentery in cows: an enigma resolved? Cornell Vet. 80(4):303-311.

Saif L.J., Redman D.R., Brock K.V., Kohler E.M. \& Heckert R.A. 1988. Winter dysentery in adult dairy cattle: detection of coronavirus in the faeces. Vet. Rec. 123(11):300-301.

Saif L.J., Brock K.V., Redman D.R. \& Kohler E.M. 1991. Winter dysentery in dairy herds: electron microscopic and serological evidence for an association with coronavirus infection. Vet. Rec. 128(19):447-449.

Smith D.R., Tsunemitsu H., Heckert R.A. \& Saif L.J. 1996. The evaluation of two antigen capture ELISAs employing polyclonal or monoclonal antibodies for detecting bovine coronavirus. J. Vet. Diagn. Invest. 8(1):99-105.

Schmitz M. 2006. Caracterização patológica e imuno-histoquímica da infecção pelo vírus da diarréia viral bovina. Dissertação de Mestrado, Faculdade de Medicina Veterinária, Universidade Federal do Rio Grande do Sul, Porto Alegre. 63p.

Takahashi E., Inaba Y., Sato K., Ito Y., Kurogi H., Akashi H., Satoda K. \& Omori T. 1980. Epizootic diarrhoea of adult cattle associated with a coronavirus-like agent. Vet. Microbiol. 5(2):151-154.
Travén M., Sundberg J., Larsson B. \& Niskanen R. 1993. Winter dysentery diagnosed by farms in dairy herds in central Sweden: Incidence, clinical signs and protective immunity. Vet. Rec. 133(13): 315-318.

Travén M., Näslund K., Linde N., Silván A., Fossum C., Hendlund K.O. \& Larsson B. 2001. Experimental reproduction of winter dysentery in lactating cows using BCV: Comparison with BCV infection in milk-fed calves. Vet. Microbiol. 81(2):127-151.

Ueno H. \& Gonçalves P.C. 1998. Manual para Diagnóstico das Helmintoses de Ruminantes. 4aㅡ ed. Japan International Cooperation Agency, Porto Alegre. 143p.

Van Kruiningen H.J., Hill D.L., Tilton R.C. \& Ryan R.W. 1985. Winter dysentery on dairy cattle: recent findings. Comp. Cont. Educ. 7(10):S591-S599.

Van Kruiningen H.J., Khairallah L.H., Sasseville V.G., Wyand M.S. \& Post J.E. 1987. Calfhood coronavirus enterocolitis: a clue to the etiology of winter dysentery. Vet. Pathol. 24(6):564-567.

Zhang Z., Andrews G.A., Chard-Bergstrom C., Minocha H.C. \& Kapil S. 1997. Application of immunohistochemistry and in situ hybridization for detection of bovine coronavirus in paraffin-embedded, formalinfixed intestines. J. Clin. Microbiol. 35(11):2964-2965. 